Check for updates

Cite this: RSC Adv., 2017, 7, 48039

Received 1st September 2017 Accepted 9th October 2017

DOI: $10.1039 / c 7 r a 09723 a$

rsc.li/rsc-advances

\section{Hybridizing $\mathrm{Fe}_{3} \mathrm{O}_{4}$ nanocrystals with nitrogen- doped carbon nanowires for high-performance supercapacitors $\dagger$}

\begin{abstract}
Jizhang Chen, (D)*a Qiongyu Chen, ${ }^{a}$ Junling $\mathrm{Xu}^{\mathrm{b}}$ and Ching-Ping Wong ${ }^{\mathrm{b}}$
This study develops a facile approach to anchor $\mathrm{Fe}_{3} \mathrm{O}_{4}$ nanocrystals uniformly onto nitrogen-doped carbon nanowires (NCN). The influence of the ratio of $\mathrm{Fe}_{3} \mathrm{O}_{4}$ to $\mathrm{NCN}$ on the structure and pseudocapacitance performance of the nanocomposite is investigated systematically. It is found that the best performance is realized when the mass percentage of $\mathrm{Fe}_{3} \mathrm{O}_{4}$ is $65.9 \%$. Benefiting from the synergistic effect of the nanostructure and conductive matrix, the optimized nanocomposite delivers high specific capacitance (541.7 $\mathrm{F} \mathrm{g}^{-1}$ at $1 \mathrm{~A} \mathrm{~g}^{-1}$ ), superior rate capability (337.1 $\mathrm{F} \mathrm{g}^{-1}$ at $10 \mathrm{~A} \mathrm{~g}^{-1}$ ), as well as good cyclability. This nanocomposite is also used as the anode material for assembling an asymmetric supercapacitor, which exhibits a high specific energy of $59.1 \mathrm{~W} \mathrm{~h} \mathrm{~kg}^{-1}$ and high specific power of $17.85 \mathrm{~kW} \mathrm{~kg}^{-1}$. The results manifest the great potential of this nanocomposite for next-generation high-power applications.
\end{abstract}

\section{Introduction}

Among various electrochemical energy storage devices, supercapacitors are well-known for their high specific power and long life span, thus holding great promise for a wide range of applications, such as energy recovery systems, backup power systems, smart grids, and high-rate power sources (e.g., mining shovels and mobile laser weapons). ${ }^{1}$ According to different charge storage mechanisms, supercapacitors can be classified as electric double-layer capacitors (EDLCs) and pseudocapacitors. ${ }^{2}$ EDLCs beat batteries in terms of specific power, whereas their specific energy is rather low, due to the fact that the energy storage of EDLCs is based on surface ion adsorption. ${ }^{3}$ Unlike EDLCs, pseudocapacitors store charges via surface and nearsurface redox reactions, as a result, their specific energy is significantly higher than that of EDLCs. ${ }^{4}$ Therefore, pseudocapacitors are now considered as promising alternative or complement to batteries, especially under the circumstances when high power delivery and/or fast energy harvesting are required. Nevertheless, the specific energy of currently developed pseudocapacitors is still much lower than that of batteries due to the following two reasons. One reason is that the interior bulk of pseudocapacitive materials hardly contributes to the energy storage, due to poor electronic and ionic conductivities.

${ }^{a}$ College of Materials Science and Engineering, Nanjing Forestry University, Nanjing 210037, China. E-mail: jizhang.chen@hotmail.com

${ }^{b}$ Department of Electronic Engineering, The Chinese University of Hong Kong, New Territories, Hong Kong

$\dagger$ Electronic supplementary information (ESI) available: SEM and TEM image, XRD patterns, XPS spectra, Nyquist plots, comparison of specific capacitance. See DOI: $10.1039 / \mathrm{c} 7 \mathrm{ra0} 9723 \mathrm{a}$
The other is that aqueous electrolytes in pseudocapacitors have a relatively narrow electrochemical stability window $(<2.0 \mathrm{~V})$.

In order to push forward the technology of supercapacitors, many research efforts have been devoted to exploring highcapacitance pseudocapacitive materials. At present, Fe-based materials are regarded as the best anode candidates for pseudocapacitors, principally because of their suitable negative working window and large theoretical specific capacitance. ${ }^{4-8}$ Besides, these materials, including $\mathrm{Fe}_{2} \mathrm{O}_{3}, \mathrm{Fe}_{3} \mathrm{O}_{4}, \mathrm{FeOOH}, \mathrm{FeS}_{2}$, and $\mathrm{FeWO}_{4}$, are earth-abundant, cost-effective, less toxic, and environmentally benign. However, these materials suffer from sluggish charge transports, which make their practical capacitances oftentimes much lower than the theoretically predicted values. To tackle such limitation, three strategies have been proposed to tailor the morphology and structure of Fe-based pseudocapacitive materials. The first strategy is to construct nanostructures, like thin film, ${ }^{, 10}$ nanoparticles,${ }^{11}$ nanorods,${ }^{12-14}$ nanoneedles ${ }^{15}$ nanowires,${ }^{16}$ nanobelts, ${ }^{17}$ nanotubes, ${ }^{18}$ nanosheets, ${ }^{19}$ nanoflakes ${ }^{20}$ so as to enlarge surface active sites and shorten charge transport distances. The second strategy extends the first one by employing hollow or porous structures, which render sufficient exposure of active sites to the electrolyte. ${ }^{21-24}$ The third strategy is to build heterostructures that incorporate Fe-based materials with electrically conductive matrixes, e.g., graphene, ${ }^{25-29}$ carbon nanotubes (CNTs), ${ }^{30}$ carbon nanofibers (CNFs), ${ }^{31}$ poly(3,4-ethylenedioxythiophene) (PEDOT), ${ }^{32,33}$ polyaniline (PANI), ${ }^{34}$ by taking advantage of fast electronic transport of the matrixes. These strategies can in principle facilitate charge transports, thus reducing electrochemical polarization and enhancing pseudocapacitive kinetics.

Previously, we reported graphene/porous $\mathrm{Fe}_{2} \mathrm{O}_{3}$ nanocomposite, which combines the merits of the above-mentioned 
three strategies. ${ }^{35}$ Although excellent pseudocapacitive performances were obtained, the synthesis procedure is too complicated to be scaled up. In this study, we focus on improving the performance of magnetite $\mathrm{Fe}_{3} \mathrm{O}_{4}$, whose electrical conductivity is more than 16 orders of magnitude higher than that of hematite $\mathrm{Fe}_{2} \mathrm{O}_{3} \cdot{ }^{36,37}$ High specific capacitance, superior rate capability, and good cyclability are realized through introducing nitrogen-doped carbon nanowires (NCN) as the conductive matrix. Moreover, the synthesis method is facile, scalable, and cost-effective. We also assemble an asymmetric supercapacitor (ASC) device by using $\mathrm{NCN} @ \mathrm{Fe}_{3} \mathrm{O}_{4}$ and $\mathrm{CNT} @ \mathrm{Co}-\mathrm{Ni}$ layered double hydroxide (LDH) as the anode and cathode materials, respectively. The device exhibits both high specific energy and high specific power.

\section{Experimental procedure}

\section{Materials synthesis}

Typically, $125 \mathrm{~mL}$ aqueous solution containing $0.02 \mathrm{M}$ cetyl trimethyl ammonium bromide (CTAB) and $0.02 \mathrm{M}$ oxalic acid was stirred at room temperature until CTAB was completely dissolved. Then, this solution was added by $0.275 \mathrm{~mL}$ pyrrole and stirred for $1 \mathrm{~h}$, followed by the addition of $20 \mathrm{~mL} 0.2 \mathrm{M}$ ammonium persulfate (APS) aqueous solution. After $4 \mathrm{~h}$ vigorous stirring at room temperature, black precipitate (polypyrrole (PPy) nanowires) was centrifugated out and washed with de-ionized (DI) water and ethanol. Around $200 \mathrm{mg}$ PPy per batch was obtained. For the synthesis of $\mathrm{NCN} @ \mathrm{Fe}_{3} \mathrm{O}_{4}, 400 \mathrm{mg} \mathrm{PPy}$ nanowires were dispersed into $40 \mathrm{~mL}$ ethanol containing certain amount of $\mathrm{Fe}\left(\mathrm{NO}_{3}\right)_{3} \cdot 9 \mathrm{H}_{2} \mathrm{O}$ by sonication and stirring. Subsequently, the solution was kept at stirring at $50{ }^{\circ} \mathrm{C}$ until ethanol was completely evaporated. Finally, the resultant product was annealed in a tube furnace at $550{ }^{\circ} \mathrm{C}$ for $2 \mathrm{~h}$ under an $\mathrm{Ar}$ stream. Through varying the amount of $\mathrm{Fe}\left(\mathrm{NO}_{3}\right)_{3} \cdot 9 \mathrm{H}_{2} \mathrm{O}$, $\mathrm{NCN} @ \mathrm{Fe}_{3} \mathrm{O}_{4}$ products with different mass ratio of $\mathrm{Fe}_{3} \mathrm{O}_{4}$ to NCN were obtained. That is, 0.994, 1.987, 2.982, and $3.976 \mathrm{~g}$ $\mathrm{Fe}\left(\mathrm{NO}_{3}\right)_{3} \cdot 9 \mathrm{H}_{2} \mathrm{O}$ led to the formation of NCN@Fe1, NCN@Fe2, NCN@Fe3, and NCN@Fe4, corresponding to the stoichiometric mass ratio of $\mathrm{Fe}_{3} \mathrm{O}_{4}$ to NCN being $1: 1,2: 1,3: 1$, and $4: 1$, respectively. For comparison, neat NCN was obtained by annealing PPy nanowires at $550{ }^{\circ} \mathrm{C}$ for $2 \mathrm{~h}$ under $\mathrm{Ar}$ atmosphere without the addition of $\mathrm{Fe}\left(\mathrm{NO}_{3}\right)_{3} \cdot 9 \mathrm{H}_{2} \mathrm{O}$. On average, $200 \mathrm{mg}$ PPy nanowires can generate $98.4 \mathrm{mg}$ NCN.

\section{Characterization}

Field emission scanning electron microscope (FE-SEM, NOVA NanoSEM 230, FEI) and transmission electron microscope (TEM, JEM-2100F, JEOL) equipped with an energy dispersive Xray spectroscopy (EDX) detector were used to characterize the morphology, structure, and elemental compositions. X-ray diffraction (XRD) patterns were collected using a Da Vinci D8 ADVANCE diffractometer with $\mathrm{Cu} \mathrm{K} \alpha$ radiation source $(\lambda=$ $0.1540598 \mathrm{~nm}$ ). Raman spectra were recorded from a Thermo Scientific DXR Raman Spectrometer $(\lambda=532 \mathrm{~nm})$. The mass ratios of $\mathrm{Fe}_{3} \mathrm{O}_{4}$ to NCN were measured on a thermogravimetric analyzer (TGA, Q5000 IR, TA Instruments) by heating samples in
$\mathrm{O}_{2}$ from 50 to $900{ }^{\circ} \mathrm{C}$ at a heating rate of $10{ }^{\circ} \mathrm{C} \mathrm{min}^{-1}$. Investigation of the surface chemical composition was performed on an X-ray photoelectron spectroscopy (XPS, ESCALAB 250Xi, Thermo Scientific).

\section{Electrochemical measurements}

A slurry of $80 \mathrm{wt} \%$ active material, $10 \mathrm{wt} \%$ carbon black (Super$\mathrm{P}$ ), and $10 \mathrm{wt} \%$ polyvinylidene difluoride (PVDF) dispersed in $\mathrm{N}$ methylpyrrolidone (NMP) was pasted onto nickel foams and then dried at $110{ }^{\circ} \mathrm{C}$ under vacuum for $12 \mathrm{~h}$. Three-electrode measurements were performed on a CHI 660E electrochemical workstation using the obtained Ni foam electrode, $\mathrm{Pt}$ plate, $\mathrm{Hg} / \mathrm{HgO}$ electrode ( $1 \mathrm{M} \mathrm{KOH})$, and $3 \mathrm{M} \mathrm{KOH}$ aqueous solution as the working electrode, counter electrode, reference electrode, and electrolyte, respectively. Cyclic voltammetry (CV) and galvanostatic charging/discharging (GCD) tests were conducted at different scan rates and current densities (based on the total bass of NCN and $\mathrm{Fe}_{3} \mathrm{O}_{4}$ ). Electrochemical impedance spectroscopy (EIS) measurements were carried out with frequency ranging from $10 \mathrm{mHz}$ to $100 \mathrm{kHz}$ and the amplitude being set at $5 \mathrm{mV}$. For two-electrode measurements, NCN@Fe2, CNT@Co-Ni LDH, and $3 \mathrm{M} \mathrm{KOH}$ aqueous solution served as the negative electrode material, positive electrode material, and electrolyte, respectively, to assemble an ASC device. The synthesis process of CNT@Co-Ni LDH can be found in our previous report. ${ }^{35}$ Prior to the ASC assembly, the mass ratio of NCN@Fe2 to CNT@Co-Ni LDH was balanced according to: $q_{+}=$ $q_{-}$. CV and GCD tests were carried out on the basis of the total mass of NCN@Fe2 and CNT@Co-Ni LDH.

\section{Results and discussion}

Fig. 1(a) depicts the schematic for fabricating NCN@Fe2. First, nitrogen-rich PPy nanowires were synthesized by a facile solution method. Then, $\mathrm{Fe}\left(\mathrm{NO}_{3}\right)_{3}$ as the Fe precursor was casted onto the surface of PPy nanowires, followed by calcination at $550{ }^{\circ} \mathrm{C}$ in Ar, during which PPy was carbonized, accompanied by the transformation of $\mathrm{Fe}^{3+}$ precursor into $\mathrm{Fe}_{3} \mathrm{O}_{4}$. As such, $\mathrm{Fe}_{3} \mathrm{O}_{4}$ was anchored onto the surface of NCN. The SEM images of PPy and NCN are shown in Fig. S1 (ESI $\dagger$ ), suggesting that PPy has a nanowire morphology while NCN inherits that morphology. Fig. 1(b)-(d) reveal that NCN@Fe2 is also composed of nanowires, implying that $\mathrm{Fe}_{3} \mathrm{O}_{4}$ is anchored on NCN uniformly. By comparing Fig. S1(d) and (e) $\dagger$ (NCN) and Fig. 1(c) and (d) (NCN@Fe-2), we can see that the edge of nanowires becomes indistinct in NCN@Fe2, due to the coating of $\mathrm{Fe}_{3} \mathrm{O}_{4}$. If further comparing higher magnification TEM images in Fig. 1 (e) and $\mathrm{S} 1(\mathrm{f}), \uparrow$ we can clearly see that NCN is decorated with $\mathrm{Fe}_{3} \mathrm{O}_{4}$ nanocrystals in NCN@Fe2. The selected area electron diffraction (SAED) pattern in the inset of Fig. 1(e) displays six rings, which are in good agreement with (220), (311), (400), (422), (511), and (440) crystalline planes of $\mathrm{Fe}_{3} \mathrm{O}_{4}$ (JCPDS 65-3107) with a cubic lattice system from the inner to the outer. The formation of $\mathrm{Fe}_{3} \mathrm{O}_{4}$ is further evidenced by the high-resolution (HR) TEM image in Fig. 1(f), which exhibits lattice spacings of $0.25,0.49$, and $0.21 \mathrm{~nm}$, matching well with the (311), (111), and (400) planes of $\mathrm{Fe}_{3} \mathrm{O}_{4}$, respectively. In order to study the 

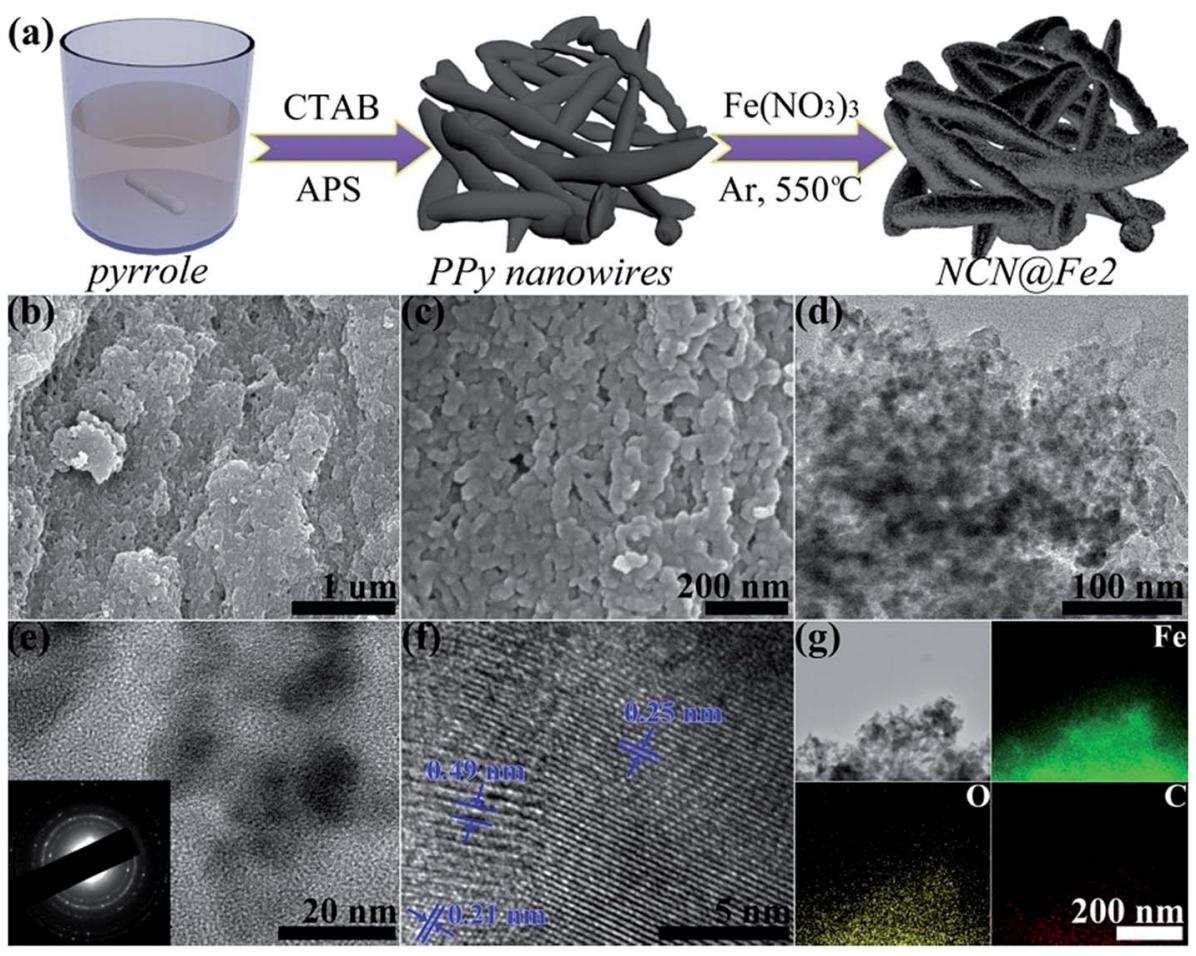

Fig. 1 (a) Illustration of the fabrication process, (b, c) SEM images, (d-f) TEM images, and (g) EDX elemental maps of NCNaFe2.

elemental distribution in NCN@Fe2, we employed EDX mapping, as shown in Fig. $1(\mathrm{~g})$. Fe and $\mathrm{O}$ elements are observed to coincide with $\mathrm{C}$ element, confirming the formation of $\mathrm{Fe}_{3} \mathrm{O}_{4}$ on the NCN surface.

The crystalline structures of the products were identified by XRD measurements and the resultant patterns are presented in Fig. 2(a). In NCN, two humps centered at around $27.5^{\circ}$ and $42.0^{\circ}$ arise from (002) and (100) planes of the pseudographitic carbon, indicative of poor ordering of graphene domains. ${ }^{38}$ After the incorporation of $\mathrm{Fe}_{3} \mathrm{O}_{4}$, all products show nearly identical patterns and the two humps from NCN still exist, implying small particle size and low crystallinity of $\mathrm{Fe}_{3} \mathrm{O}_{4}$. Take NCN@Fe2 for example, the peaks at $30.1^{\circ}, 35.5^{\circ}, 43.0^{\circ}, 56.9^{\circ}$, and $62.5^{\circ}$ can be indexed as (220), (311), (400), (511), and (440) planes of $\mathrm{Fe}_{3} \mathrm{O}_{4}$. In order to investigate the formation process of $\mathrm{NCN} @ \mathrm{Fe}_{3} \mathrm{O}_{4}$, we also used XRD technique to characterize different products when the raw material or annealing temperature was altered, as shown in Fig. S2 (ESI $\dagger$ ). It can be seen that the $\mathrm{Fe}\left(\mathrm{NO}_{3}\right)_{3} \cdot 9 \mathrm{H}_{2} \mathrm{O}$ precursor was hydrolyzed to $\mathrm{Fe}(\mathrm{OH})_{3}$ after the ethanol solvent was evaporated. The $\mathrm{Fe}(\mathrm{OH})_{3}$ can be bound to PPy nanowires due to the mutual effects of surface adsorption and electrostatic interaction. Then during the annealing process, $\mathrm{Fe}(\mathrm{OH})_{3}$ was converted to $\mathrm{Fe}_{3} \mathrm{O}_{4}$, producing NCN@ $\mathrm{Fe}_{3} \mathrm{O}_{4}$.

Raman measurements were also conducted to further confirm the phase and composition of NCN-based products, as shown in Fig. 2(b). NCN exhibits a broad disorder-induced D band at $\sim 1359 \mathrm{~cm}^{-1}$ and a broad graphitic in-plane vibrational $\mathrm{G}$ band at $\sim 1575 \mathrm{~cm}^{-1}$, which are two typical bands of carbonaceous materials. ${ }^{35,39}$ Besides, there exists a hump from 2500 to $3200 \mathrm{~cm}^{-1}$, relating with $2 \mathrm{D}$ and $\mathrm{D}+\mathrm{G}$ bands. After the introduction of $\mathrm{Fe}_{3} \mathrm{O}_{4}$, five new peaks appear in the low frequency region of 100 to $1000 \mathrm{~cm}^{-1}$. These peaks are all characteristic of $\mathrm{Fe}_{3} \mathrm{O}_{4}$, i.e. $\mathrm{E}_{\mathrm{g}}$ mode $(212,275,387$ and $479 \mathrm{~cm}^{-1}$ ) and $\mathrm{A}_{1 \mathrm{~g}}$ mode $\left(585 \mathrm{~cm}^{-1}\right) \cdot{ }^{40,41}$ As the content of $\mathrm{Fe}_{3} \mathrm{O}_{4}$ increases, the intensity of these peaks becomes stronger. In addition to these peaks, broad peaks at $\sim 1280 \mathrm{~cm}^{-1}$ also come from $\mathrm{Fe}_{3} \mathrm{O}_{4}{ }^{40,41}$ Different from XRD measurements, the intensity of Raman bands from NCN decreases considerably when increasing the amount of $\mathrm{Fe}_{3} \mathrm{O}_{4}$, due to different detection depth of XRD and Raman techniques.

TG analysis was conducted in $\mathrm{O}_{2}$ atmosphere to determine the weight percentages of $\mathrm{Fe}_{3} \mathrm{O}_{4}$ in the NCN-based products. During high-temperature treatment, $\mathrm{Fe}_{3} \mathrm{O}_{4}$ was oxidized to $\mathrm{Fe}_{2} \mathrm{O}_{3}$, while NCN was burnt into $\mathrm{CO}_{2}$. According to the weight loss in the TG curves (Fig. 2(c)), the weight percentages of $\mathrm{Fe}_{3} \mathrm{O}_{4}$ are estimated to be $45.9 \%, 65.9 \%, 78.4 \%$, and $89.0 \%$ in NCN@Fe1, NCN@Fe2, NCN@Fe3, and NCN@Fe4, respectively. XPS characterization was carried out to study the chemical contents and valence states in NCN@Fe2, as shown in Fig. 2(d) and S3 (ESI $\dagger$ ). The survey spectrum in Fig. S3(a) $\dagger$ exclusively reveals $\mathrm{C}, \mathrm{O}, \mathrm{Fe}$, and $\mathrm{N}$ elements, demonstrating the dispersion of iron oxide in N-doped carbon matrix. In Fig. 2(d), the HR XPS spectrum for the Fe 2p core level is consistent with that of $\mathrm{Fe}_{3} \mathrm{O}_{4}$ in other reports. ${ }^{42}$ Two main peaks at $710.7 \mathrm{eV}$ and $724.1 \mathrm{eV}$ accompanied by their satellite peaks at 718.2 and $732.8 \mathrm{eV}$ are characteristic of $\mathrm{Fe}^{3+}$, while 712.8 and $726.4 \mathrm{eV}$ are assigned to $\mathrm{Fe}^{2+} 2 \mathrm{p} 3 / 2$ and $\mathrm{Fe}^{2+}$ 2p1/2, respectively. ${ }^{13}$ The deconvolution of the $\mathrm{C} 1 \mathrm{~s}$ HR spectrum is exhibited in Fig. $\mathrm{S} 3(\mathrm{~b}) . \dagger$ The most pronounced peaks is located at $284.7 \mathrm{eV}$, which is characteristic 
a

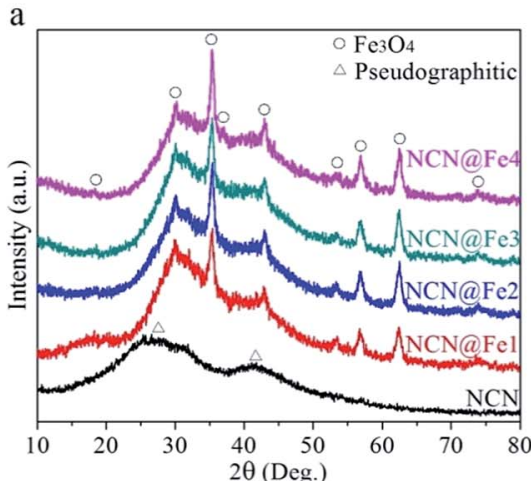

$\mathrm{c}$

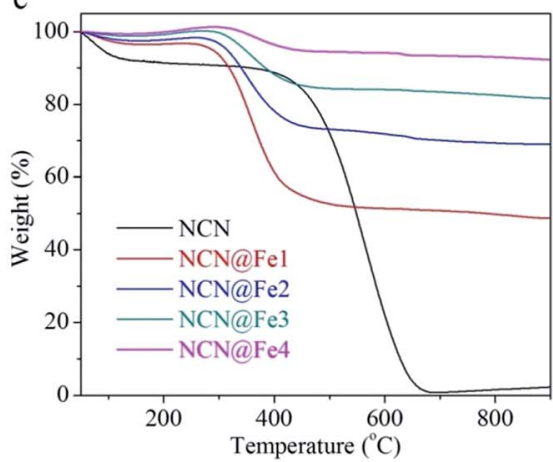

b

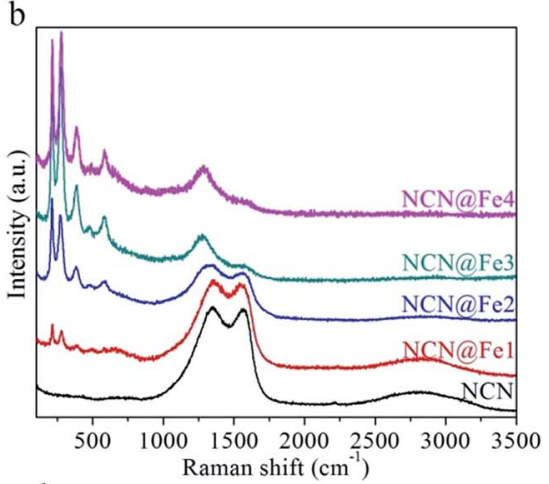

d

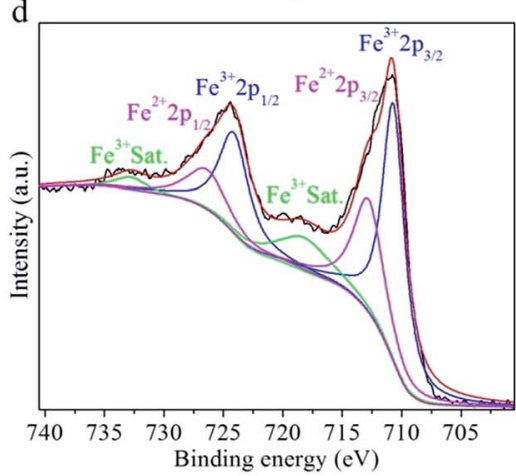

Fig. 2 (a) XRD patterns, (b) Raman spectra, (c) TG curves of NCN, NCNaFe1, NCNaFe2, NCNaFe3, and NCNaFe4. (d) Fe 2p HR XPS spectrum of $\mathrm{NCNaFe2}$.

of the $\mathrm{sp}^{2}$ graphitic lattice $(\mathrm{C}-\mathrm{C}$ and $\mathrm{C}=\mathrm{C})$, while three other subpeaks at 288.1, 286.2, and $285.4 \mathrm{eV}$ are associated with $\mathrm{O}-$ $\mathrm{C}=\mathrm{O}, \mathrm{C}=\mathrm{N}(\& \mathrm{C}=\mathrm{O})$, and $\mathrm{C}-\mathrm{N}(\& \mathrm{C}-\mathrm{O})$ functional groups, respectively. ${ }^{43}$ In Fig. $\mathrm{S} 3(\mathrm{c}), \dagger$ the $\mathrm{N}$ 1s signal is derived from the NCN matrix, and contains three subpeaks at 400.3, 399.4, and $398.7 \mathrm{eV}$, corresponding to quaternary $\mathrm{N}$, pyrrolic $\mathrm{N}$, and pyridinic $\mathrm{N}$, respectively. ${ }^{\mathbf{4 4 , 4 5}}$ Specifically, the $\mathrm{N}$ doping can donate extra electrons that increase the electrical conductivity. And the $\mathrm{O}$ 1s HR spectrum (Fig. S3(d) $\dagger$ ) can be fitted into four peaks at 533.4, 532.1, 531.3, and $530.3 \mathrm{eV}$, in accordance with absorbed water, $\mathrm{O}-\mathrm{C}, \mathrm{O}=\mathrm{C}$, and $\mathrm{O}-\mathrm{Fe}$, respectively. ${ }^{43,46}$

$\mathrm{CV}$ and GCD measurements were performed in a threeelectrode setup to evaluate electrochemical performances of
NCN, NCN@Fe1, NCN@Fe2, NCN@Fe3, and NCN@Fe4. Fig. 3(a) compares CV curves of different products at a scan rate of $5 \mathrm{mV} \mathrm{s}^{-1}$. The CV curve of NCN is similar to the rectangular, which is characteristic of EDCL materials. And NCN yields the lowest integral area among all the products, indicating its low specific capacitance. After $\mathrm{Fe}_{3} \mathrm{O}_{4}$ is introduced, the products exhibit redox peaks at around -0.97 and $-0.66 \mathrm{~V}$, quite different from that of NCN, suggesting the energy storage process is dominated by faradaic redox reactions. Moreover, the separation between cathodic and anodic peaks is merely $0.31 \mathrm{~V}$, considerably lower than $0.48 \mathrm{~V}$ of $\mathrm{Fe}_{2} \mathrm{O}_{3}$ in our previous report. ${ }^{35}$ Such small separation is likely to originate from the high electrical conductivity of $\mathrm{Fe}_{3} \mathrm{O}_{4}$, which is in favor of electronic
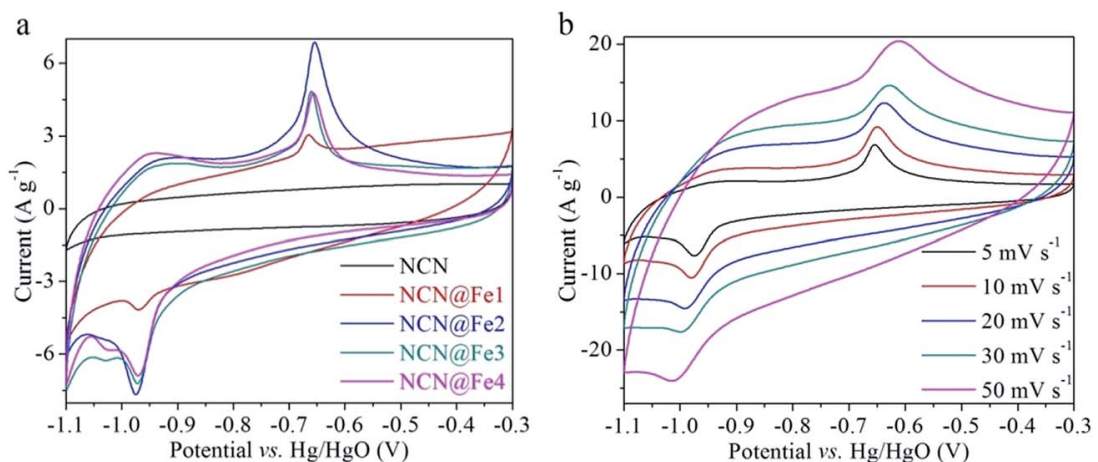

Fig. 3 (a) Comparative CV curves of NCN, NCN@Fe1, NCNaFe2, NCN@Fe3, and NCN@Fe4 at $5 \mathrm{mV} \mathrm{s}^{-1}$. (b) CV curves of NCNaFe2 at different scan rates. 
transports and therefore reduces electrochemical polarization. It is also observed that the weight percentage of $\mathrm{Fe}_{3} \mathrm{O}_{4}$ has an influence on the $\mathrm{CV}$ profile. NCN@Fe1 shows the minimum redox peaks, while NCN@Fe2 reveals the most prominent anodic peak. The rate-dependent CV curves of NCN@Fe2 are displayed in Fig. 3(b). As the scan rate is progressively increased, the anodic peak moves to higher potential, while the cathodic peak shifts to lower potential, due to stronger electrochemical polarization at a higher rate. At a low scan rate, electrons and electrolyte ions are provided with sufficient time to access the reaction sites of $\mathrm{Fe}_{3} \mathrm{O}_{4}$. When the scan rate is high, however, the charge transports within $\mathrm{Fe}_{3} \mathrm{O}_{4}$ cannot be synchronized with the rapid transfer of electrons in the external circuit. As a result, the accumulated electrons on the electrode would increase potential for charging and decrease potential for discharging. Notably, the separation between redox peaks is still low $(0.405$ $\mathrm{V)}$ at $50 \mathrm{mV} \mathrm{s}^{-1}$, suggesting fast redox kinetics of NCN@Fe2.

GCD curves of NCN, NCN@Fe1, NCN@Fe2, NCN@Fe3, and NCN@Fe4 are compared in Fig. 4(a). These GCD curves are consistent with the CV curves in Fig. 3(a). The NCN curve shows typical triangle shape of EDLCs, while $\mathrm{Fe}_{3} \mathrm{O}_{4}$-containing products show charging and discharging plateaus that are associated with the pseudocapacitive characteristic. Similar to the CV results, NCN@Fe2 reveals the most developed plateaus. In contrast, the plateaus of $\mathrm{NCN} @ \mathrm{Fe} 4$ are indistinct, which might result from too much $\mathrm{Fe}_{3} \mathrm{O}_{4}$ anchored on the NCN, setting a barrier for charge transports. Fig. 4(b) presents GCD curves of NCN@Fe2 at different current densities. The charging and discharging curves are approximately symmetric throughout all the current densities, suggesting good reversibility of
NCN@Fe2. At $1 \mathrm{~A} \mathrm{~g}^{-1}$, the charging and discharging plateaus are situated at -0.675 and $-0.932 \mathrm{~V}$, respectively. The corresponding separation $(0.257 \mathrm{~V})$ is smaller than that of the $5 \mathrm{mV}$ $\mathrm{s}^{-1} \mathrm{CV}$ curve. In addition, abrupt potential drops are observed at the beginning of the discharging curves, which originate from the equivalent series resistance $\left(R_{\mathrm{ESR}}\right)$. The $R_{\mathrm{ESR}}$ is mainly comprised of the intrinsic resistance of electrode and the ionic resistance from the electrolyte. Herein, the $R_{\mathrm{ESR}}$ average is calculated to be merely $0.87 \Omega$.

Fig. 4(c) summarizes the rate-dependent specific capacitances of NCN, NCN@Fe1, NCN@Fe2, NCN@Fe3, and NCN@Fe4. The capacitance values are calculated on the basis of the charging curves, according to the calculation procedure described in our previous reports. ${ }^{35,39,47} \mathrm{NCN}$ gives the lowest capacitances among all the products while NCN@Fe2 gives the largest capacitance throughout all the current densities. The reason why NCN@Fe2 possesses the best rate capability is that it contains a suitable amount of $\mathrm{Fe}_{3} \mathrm{O}_{4}$. If the percentage of $\mathrm{Fe}_{3} \mathrm{O}_{4}$ is too low, the capacitance of the composite would certainly be constrained. Otherwise if the percentage is too high, the charge transports within $\mathrm{Fe}_{3} \mathrm{O}_{4}$ would be insufficient. The charging capacitance of $\mathrm{NCN} @ \mathrm{Fe} 2$ reaches $541.7 \mathrm{~F} \mathrm{~g}^{-1}$ at $1 \mathrm{~A} \mathrm{~g}^{-1}$, while still maintaining $337.1,199.2$, and $121.0 \mathrm{~F} \mathrm{~g}^{-1}$ at 10,30 , and $50 \mathrm{~A} \mathrm{~g}^{-1}$, respectively. Impressively, NCN@Fe2 is superior to many Fe-based pseudocapacitive materials reported in recent three years, such as the ones listed in Table S1 (ESI $\dagger$ ), including Ti-doped $\mathrm{Fe}_{2} \mathrm{O}_{3} @ P E D O T$ $\left(311.6 \mathrm{~F} \mathrm{~g}^{-1}\right),{ }^{33} \mathrm{Fe}_{2} \mathrm{O}_{3}$ nanotubes $\left(300.1 \mathrm{~F} \mathrm{~g}^{-1}\right),{ }^{18}$ graphene/FeOOH QDs $\left(365 \mathrm{~F} \mathrm{~g}^{-1}\right),{ }^{28} \mathrm{rGO} / \mathrm{Fe}_{3} \mathrm{O}_{4}$ nanoparticles $\left(241 \mathrm{~F} \mathrm{~g}^{-1}\right),{ }^{48} \mathrm{Fe}_{3^{-}}$ $\mathrm{O}_{4}$ @hollow graphite $\left(481 \mathrm{~F} \mathrm{~g}^{-1}\right),{ }^{19} \mathrm{Fe}_{2} \mathrm{O}_{3} @ \mathrm{MnO}_{2}$ nanotubes $\left(289.9 \mathrm{~F} \mathrm{~g}^{-1}\right),{ }^{49} \mathrm{Fe}_{2} \mathrm{O}_{3}$ nanorods $\left(516.7 \mathrm{~F} \mathrm{~g}^{-1}\right),{ }^{14}$ etc.
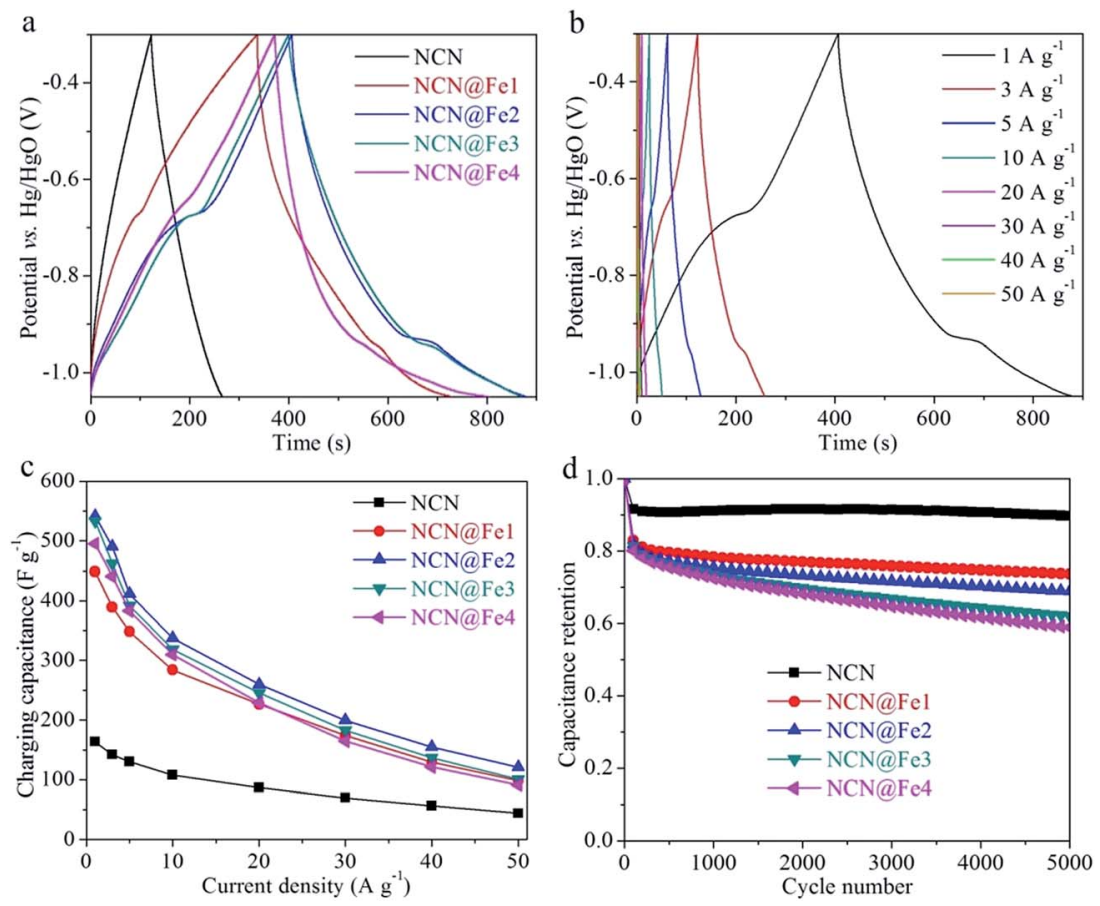

Fig. 4 (a) Comparative GCD curves at $1 \mathrm{~A} \mathrm{~g}^{-1}$, (c) rate performances and (d) cycling performances of NCN, NCN@Fe1, NCN@Fe2, NCNaFe3 and NCNaFe4. (b) GCD curves of NCNaFe2 at different current densities. 
a

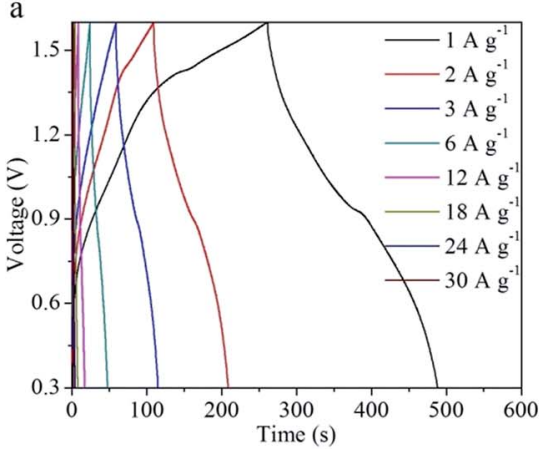

$\mathrm{b}$

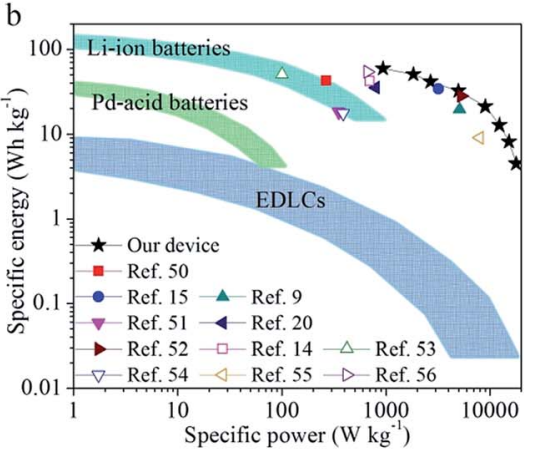

Fig. 5 (a) GCD curves of NCNaFe2//CNTaCo-Ni LDH ASC device at different current densities. (b) Ragone plots of specific energy vs. specific power for our ASC device in comparison with other Fe-based ASCs reported in recent three years.

Cycling stability is another important parameter. Fig. 4(d) shows capacitance retentions of different products as a function of the cycle number. After 5000 cycles, NCN retains rather high capacitance retention of $89.7 \%$, which is characteristic of EDLC materials. As the weight percentage of $\mathrm{Fe}_{2} \mathrm{O}_{3}$ rises progressively, the cyclability deteriorates gradually. This phenomenon is due to the intrinsic low cyclability of pseudocapacitive materials, that is, the large volumetric and structural changes during redox reactions inevitably bring in large capacitance loss upon repeated cycles. The NCN matrix can function as a buffer to relax these changes, resulting in better cyclability when more NCN is employed. As for NCN@Fe2, its capacitance retention is $68.9 \%$ after 5000 cycles. EIS measurements were also carried out to study different NCN-based products, as shown in Fig. S4 (ESI $\dagger$ ). The Nyquist plots were fitted with the EC-Lab software using an equivalent circuit of $R_{1}+C_{1} / R_{2}+C_{2} /\left(W_{1}+R_{3}\right)$. The bulk resistance $R_{1}$ of NCN, NCN@Fe1, NCN@Fe2, NCN@Fe3, and NCN@Fe4 is determined to be 0.559, 0.569, 0.573, 0.565, and $0.575 \Omega$, respectively. There is no obvious increase in $R_{1}$ when increasing the mass ratio of $\mathrm{Fe}_{3} \mathrm{O}_{4}$ to $\mathrm{NCN}$, implying high electrical conductivity of $\mathrm{Fe}_{3} \mathrm{O}_{4}$. Besides, the charge transfer impedance $R_{3}$ of all the NCN-based products is lower than $1 \Omega$, indicative of fast interface kinetics.

To further evaluate the NCN@Fe2 (the best performed $\mathrm{NCN} @ \mathrm{Fe}_{3} \mathrm{O}_{4}$ ), we fabricated ASC devices using NCN@Fe2 and CNT@Co-Ni LDH as the anode and cathode materials, respectively. The CNT@Co-Ni LDH was reported by us previously. ${ }^{35}$ Because the potential windows of NCN@Fe2 and CNT@Co-Ni LDH are compatible, the ASC can deliver a high open-circuit voltage of $1.6 \mathrm{~V}$, as shown in Fig. 5(a). These GVD curves are nonlinearly correlated with the potential, indicating pseudocapacitive behaviors. As the current density increases from 1, 6, to $18 \mathrm{~A} \mathrm{~g}^{-1}$, the discharging capacitance of the ASC (calculated based on the total mass of NCN@Fe2 and CNT@Co-Ni LDH) decreases from $174.5,107.8$, to $51.7 \mathrm{~F} \mathrm{~g}^{-1}$, respectively, exhibiting superior rate capability. Ragone plots of specific energy $v s$. specific power are displayed in Fig. 5(b), where the values of several state-of-the-art Fe-based ASCs reported in recent three years are also plotted., ,14,15,20,50-56 Our device exhibits high specific energy of $59.1 \mathrm{~W} \mathrm{~h} \mathrm{~kg}^{-1}$ under $937 \mathrm{~W} \mathrm{~kg}^{-1}$. Even when the specific power is increased to 4970 and $17850 \mathrm{~W} \mathrm{~kg}^{-1}$, the specific energy of our ASC still maintains 32.2 and $4.5 \mathrm{~W} \mathrm{~h} \mathrm{~kg}^{-1}$, respectively. Such energy-power performance outperforms many other Fe-based ASCs, such as $\mathrm{Fe}_{2} \mathrm{O}_{3}$ nanoflakes/PPy nanoleaves $/ / \mathrm{MnO}_{2}$ nanosheets ASC $\left(42.4 \mathrm{~W} \mathrm{~h} \mathrm{~kg}^{-1}\right.$ at $269 \mathrm{~W}$ $\left.\mathrm{kg}^{-1}\right),{ }^{50} \quad \mathrm{Fe}_{2} \mathrm{O}_{3} \quad$ nanoneedles// $\mathrm{MnO}_{2}$ nanosheets ASC (34.1 W h kg ${ }^{-1}$ at $\left.3198 \mathrm{~W} \mathrm{~kg}^{-1}\right),{ }^{15} \mathrm{Fe}_{2} \mathrm{O}_{3}$ nanorods//CoMoO ${ }_{4}$ @$\mathrm{NiMoO}_{4}$ ASC $\left(41.8 \mathrm{~W} \mathrm{~h} \mathrm{~kg}{ }^{-1}\right.$ at $\left.700 \mathrm{~W} \mathrm{~kg}{ }^{-1}\right),{ }^{14} \mathrm{rGO} / \mathrm{Fe}_{2} \mathrm{O}_{3}$ composite//CuCo $\mathrm{Cu}_{4} / \mathrm{CuO}$ nanowires ASC $\left(9.1 \mathrm{~W} \mathrm{~h} \mathrm{~kg}{ }^{-1}\right.$ at $\left.8000 \mathrm{~W} \mathrm{~kg}{ }^{-1}\right){ }^{55}$ The above-mentioned good performances of NCN@Fe2 can be ascribed to the following four facts. First, NCN offers a highly conductive path for electrons. Second, the tiny particle size of $\mathrm{Fe}_{3} \mathrm{O}_{4}$ not only provides sufficient redox reaction sites but also facilitates charge transports within $\mathrm{Fe}_{3} \mathrm{O}_{4}$. Third, NCN can accommodate volumetric expansions of $\mathrm{Fe}_{3} \mathrm{O}_{4}$, therefore preventing $\mathrm{Fe}_{3} \mathrm{O}_{4}$ from decaying during long cycles. Last but not least, $\mathrm{Fe}_{3} \mathrm{O}_{4}$ is an electrical conductor, which allows for rapid electronic transports.

\section{Conclusions}

In summary, we have developed a facile, scalable, and costeffective method to produce $\mathrm{Fe}_{3} \mathrm{O}_{4}$ nanocrystals uniformly anchored on the NCN. The nanostructure can enlarge surface active sites and shorten charge transport distances, while the conductive NCN matrix not only acts as a highway for electrons but also buffers volumetric changes of $\mathrm{Fe}_{3} \mathrm{O}_{4}$. The ratio of $\mathrm{Fe}_{3} \mathrm{O}_{4}$ to NCN is optimized systematically, and it is found that the $65.9 \%$ mass percentage of $\mathrm{Fe}_{3} \mathrm{O}_{4}$ contributes to the best pseudocapacitive performance. The optimized NCN@Fe2 nanocomposite demonstrates high specific capacitance, superior rate capability, and good cyclability. Furthermore, aqueous ASC device assembled from the NCN@Fe2 anode and CNT@Co-Ni LDH cathode exhibits high specific energy and high specific power. The results of this study show great promise of NCN@Fe2 for high-performance supercapacitors.

\section{Conflicts of interest}

There are no conflicts to declare. 


\section{Acknowledgements}

This work was supported by the Natural Science Foundation of Jiangsu Province (BK20170917) and the Scientific Research Foundation for High-Level Talents of Nanjing Forestry University (GXL2016023).

\section{References}

1 M. R. Lukatskaya, B. Dunn and Y. Gogotsi, Nat. Commun., 2016, 7, 12647.

2 Y. Wang, Y. Song and Y. Xia, Chem. Soc. Rev., 2016, 45, 59255950.

3 F. Béguin, V. Presser, A. Balducci and E. Frackowiak, Adv. Mater., 2014, 26, 2219-2251.

4 Y. Zeng, M. Yu, Y. Meng, P. Fang, X. Lu and Y. Tong, Adv. Energy Mater., 2016, 6, 1601053.

5 V. D. Nithya and N. S. Arul, J. Power Sources, 2016, 327, 297318.

6 N. Goubard-Bretesché, O. Crosnier, G. Buvat, F. Favier and T. Brousse, J. Power Sources, 2016, 326, 695-701.

7 K. A. Owusu, L. Qu, J. Li, Z. Wang, K. Zhao, C. Yang, K. M. Hercule, C. Lin, C. Shi, Q. Wei, L. Zhou and L. Mai, Nat. Commun., 2017, 8, 14264.

8 S. Yang, Y. Li, T. Xu, Y. Li, H. Fu, K. Cheng, K. Ye, L. Yang, D. Cao and G. Wang, RSC Adv., 2016, 6, 39166-39171.

9 G. S. Gund, D. P. Dubal, N. R. Chodankar, J. Y. Cho, P. Gomez-Romero, C. Park and C. D. Lokhande, Sci. Rep., 2015, 5, 12454.

10 J. S. Sagu, K. G. Wijayantha, M. Bohm, S. Bohm and T. Kumar Rout, ACS Appl. Mater. Interfaces, 2016, 8, 62776285.

11 D. Chen, S. Li, B. Xu, F. Zheng, H. Zhou, H. Yu, F. Lin and X. Zhu, RSC Adv., 2016, 6, 45023-45030.

12 L.-F. Chen, Z.-Y. Yu, J.-J. Wang, Q.-X. Li, Z.-Q. Tan, Y.-W. Zhu and S.-H. Yu, Nano Energy, 2015, 11, 119-128.

13 X. Tang, R. Jia, T. Zhai and H. Xia, ACS Appl. Mater. Interfaces, 2015, 7, 27518-27525.

14 J. Wang, L. Zhang, X. Liu, X. Zhang, Y. Tian, X. Liu, J. Zhao and Y. Li, Sci. Rep., 2017, 7, 41088.

15 Y. Li, J. Xu, T. Feng, Q. Yao, J. Xie and H. Xia, Adv. Funct. Mater., 2017, 27, 1606728.

16 Q. Tang, W. Wang and G. Wang, J. Mater. Chem. A, 2015, 3, 6662-6670.

17 J. Chen, X. Zhou, C. Mei, J. Xu, S. Zhou and C.-P. Wong, Electrochim. Acta, 2016, 222, 172-176.

18 Y.-G. Lin, Y.-K. Hsu, Y.-C. Lin and Y.-C. Chen, Electrochim. Acta, 2016, 216, 287-294.

19 H. Khani and D. O. Wipf, ACS Appl. Mater. Interfaces, 2017, 9, 6967-6978.

20 F. Li, H. Chen, X. Y. Liu, S. J. Zhu, J. Q. Jia, C. H. Xu, F. Dong, Z. Q. Wen and Y. X. Zhang, J. Mater. Chem. A, 2016, 4, 20962104.

21 Y. Liu, F. Liu, Y. Chen, J. Jiang, Y. Ai, S. Han and H. Lin, RSC Adv., 2016, 6, 23659-23665.

22 C. Fu, A. Mahadevegowda and P. S. Grant, J. Mater. Chem. A, 2016, 4, 2597-2604.
23 J. Li, W. Zhang, G. Zan and Q. Wu, Dalton Trans., 2016, 45, 12790-12799.

24 X. Xu, C. Cao and Y. Zhu, Electrochim. Acta, 2015, 155, 257262.

25 A. M. Khattak, H. Yin, Z. A. Ghazi, B. Liang, A. Iqbal, N. A. Khan, Y. Gao, L. Li and Z. Tang, $R S C A d v$., 2016, 6, 58994-59000.

26 Y. Hu, C. Guan, Q. Ke, Z. F. Yow, C. Cheng and J. Wang, Chem. Mater., 2016, 28, 7296-7303.

27 N. Li, C. Zhi and H. Zhang, Electrochim. Acta, 2016, 220, 618627.

28 J. Liu, M. Zheng, X. Shi, H. Zeng and H. Xia, Adv. Funct. Mater., 2016, 26, 919-930.

29 S. Mondal, U. Rana and S. Malik, J. Phys. Chem. C, 2017, 121, 7573-7583.

30 T. Gu and B. Wei, J. Mater. Chem. A, 2016, 4, 12289-12295.

31 C. Guan, W. Zhao, Y. Hu, Q. Ke, X. Li, H. Zhang and J. Wang, Adv. Energy Mater., 2016, 6, 1601034.

32 E. Pardieu, S. Pronkin, M. Dolci, T. Dintzer, B. P. Pichon, D. Begin, C. Pham-Huu, P. Schaaf, S. Begin-Colin and F. Boulmedais, J. Mater. Chem. A, 2015, 3, 22877-22885.

33 Y. Zeng, Y. Han, Y. Zhao, Y. Zeng, M. Yu, Y. Liu, H. Tang, Y. Tong and X. Lu, Adv. Energy Mater., 2015, 5, 1402176.

34 X. F. Lu, X. Y. Chen, W. Zhou, Y. X. Tong and G. R. Li, ACS Appl. Mater. Interfaces, 2015, 7, 14843-14850.

35 J. Chen, J. Xu, S. Zhou, N. Zhao and C.-P. Wong, Nano Energy, 2015, 15, 719-728.

36 K. K. Lee, S. Deng, H. M. Fan, S. Mhaisalkar, H. R. Tan, E. S. Tok, K. P. Loh, W. S. Chin and C. H. Sow, Nanoscale, 2012, 4, 2958-2961.

37 D. Reisinger, P. Majewski, M. Opel, L. Alff and R. Gross, Appl. Phys. Lett., 2004, 85, 4980-4982.

38 J. Ding, H. Wang, Z. Li, K. Cui, D. Karpuzov, X. Tan, A. Kohandehghan and D. Mitlin, Energy Environ. Sci., 2015, 8, 941-955.

39 J. Chen, J. Xu, S. Zhou, N. Zhao and C.-P. Wong, Nano Energy, 2016, 25, 193-202.

40 S. Lalwani, V. Sahu, R. B. Marichi, G. Singh and R. K. Sharma, Electrochim. Acta, 2017, 224, 517-526.

41 E. Mitchell, R. K. Gupta, K. Mensah-Darkwa, D. Kumar, K. Ramasamy, B. K. Gupta and P. Kahol, New J. Chem., 2014, 38, 4344.

42 C. Fu, A. Mahadevegowda and P. S. Grant, J. Mater. Chem. A, 2015, 3, 14245-14253.

43 G. Zhu, C. Xi, Y. Liu, J. Zhu and X. Shen, J. Mater. Chem. A, 2015, 3, 7591-7599.

44 H. Wang, T. Maiyalagan and X. Wang, ACS Catal., 2012, 2, 781-794.

45 N. P. Wickramaratne, J. Xu, M. Wang, L. Zhu, L. Dai and M. Jaroniec, Chem. Mater., 2014, 26, 2820-2828.

46 S. Yang, C. Wang, L. Ma, Y. Peng, Z. Qu, N. Yan, J. Chen, H. Chang and J. Li, Catal. Sci. Technol., 2013, 3, 161-168.

47 J. Chen, J. Xu, S. Zhou, N. Zhao and C.-P. Wong, J. Mater. Chem. A, 2015, 3, 17385-17391.

48 L. Li, P. Gao, S. Gai, F. He, Y. Chen, M. Zhang and P. Yang, Electrochim. Acta, 2016, 190, 566-573. 
49 G. Nie, X. Lu, M. Chi, Y. Zhu, Z. Yang, N. Song and C. Wang, Electrochim. Acta, 2017, 231, 36-43.

50 P.-Y. Tang, L.-J. Han, A. Genç, Y.-M. He, X. Zhang, L. Zhang, J. R. Galán-Mascarós, J. R. Morante and J. Arbiol, Nano Energy, 2016, 22, 189-201.

51 H. Fan, R. Niu, J. Duan, W. Liu and W. Shen, ACS Appl. Mater. Interfaces, 2016, 8, 19475-19483.

52 J. Li, W. Lu, Y. Yan and T.-W. Chou, J. Mater. Chem. A, 2017, 5, 11271-11277.
53 H. Xia, C. Hong, B. Li, B. Zhao, Z. Lin, M. Zheng, S. V. Savilov and S. M. Aldoshin, Adv. Funct. Mater., 2015, 25, 627-635.

54 A. Mahmood, R. Zou, Q. Wang, W. Xia, H. Tabassum, B. Qiu and R. Zhao, ACS Appl. Mater. Interfaces, 2016, 8, 2148-2157.

55 Y. Wang, C. Shen, L. Niu, R. Li, H. Guo, Y. Shi, C. Li, X. Liu and Y. Gong, J. Mater. Chem. A, 2016, 4, 9977-9985.

56 N. R. Chodankar, D. P. Dubal, A. C. Lokhande, A. M. Patil, J. H. Kim and C. D. Lokhande, Sci. Rep., 2016, 6, 39205. 